\title{
The Effect of Backpack Load on Muscle Activities of the Trunk and Lower Extremities and Plantar Foot Pressure in Flatfoot
}

\author{
Hohee Son, PhD, $\mathrm{PT}^{1)}$ \\ 1) Department of Physical Therapy, College of Health Sciences, Catholic University of Pusan: 57 \\ Oryundae-ro, Geumjeong-gu, Busan 609-757, Republic of Korea
}

\begin{abstract}
Purpose] The purpose of this study was to investigate the changes in muscle activation of the trunk and lower extremities and plantar foot pressure due to backpack loads of $0,10,15$, and $20 \%$ of body weight during level walking in individuals with flatfoot. [Methods] Fourteen young flatfoot subjects and 12 normal foot subjects participated in this study. In each session, the subjects were assigned to carry a backpack load, and there were four level walking modes: (1) unloaded walking (0\%), (2) 10\% body weight (BW) load, (3) 15\% BW load, and (4) $20 \%$ BW load. Trunk and lower extremity muscle activities were recorded by surface EMG, and contact area and plantar foot pressure were determined using a RS scan system. [Results] The erector spinae, vastus medialis, tibialis anterior and gastrocnemius muscle activities, but not the rectus femoris and rectus abdominis muscle activities of flatfoot subjects significantly and progressively increased as load increased in flatfoot subjects. Contact area and pressure of the lateral and medial heel zones were significantly increased too. [Conclusion] Based on this data, the weight of a backpack could influence muscle activation and plantar foot pressure in flatfoot.

Key words: Flatfoot, Backpack, Plantar pressure
\end{abstract}

(This article was submitted Apr. 25, 2013, and was accepted May 31, 2013)

\section{INTRODUCTION}

The foot is a very complex multi-segmented structure. Shock absorption, stability and propulsion are the main biomechanical functions of the foot. Measurement of foot pressure distribution (FPD) is clinically useful for evaluation of foot and gait pathologies ${ }^{1,2)}$.

Individuals with flatfoot may be at increased risk for the development of many lower extremity overuse injuries including metatarsal stress fractures, iliotibial band syndrome, and patellofemoral pain syndrome ${ }^{3)}$. Mechanical overloading in flatfoot has been attributed primarily to excessive motion and muscle activity. Runners with low arches are at increased risk for developing second and third metatarsal stress fractures, and have an increase in rearfoot eversion velocity and eversion excursion ${ }^{4,5)}$. Backpack load carriage also leads to higher trunk forward lean compared with the normal gait. The most common problem with backpacks is the increased weight on the back. Many studies on backpack-related medical injuries have been reported ${ }^{6-8)}$ Pascoe et al. ${ }^{9)}$ reported that the most common symptoms associated with overweight backpacks were muscle soreness, back pain, numbness, and shoulder pain. It is widely believed that a person with a postural type of flatfoot has

Corresponding author. Hohee Son (e-mail: sonhh@cup.ac.kr) (C)2013 The Society of Physical Therapy Science

This is an open-access article distributed under the terms of the Creative Commons Attribution Non-Commercial No Derivatives (by-ncnd) License $<$ http://creativecommons.org/licenses/by-nc-nd/3.0/> . increased susceptibility to mechanical overloading of their foot structure ${ }^{10)}$. Study of the ground reaction forces (GRF) during load carriage can provide relevant information about the mechanisms of gait, and provide a measure of the impact forces acting on the foot. It is therefore essential in the understanding and prevention of lower extremity injuries in flatfoot. However, most of the research about the effect of wearing backpacks in adults focuses on use of backpacks for recreation or how carrying heavy loads affects military personnel ${ }^{7,11,12)}$. There are no previous studies that have examined changes in flatfoot subjects during gait with different backpack weights.

The purpose of this study was to investigate the changes in muscle activation of the trunk and lower extremities and plantar foot pressure with backpack loads of $0,10,15$, and $20 \%$ of body weight while level walking in flatfoot individuals and to recommend suitable backpack weight limitations for flatfoot subjects. It was hypothesized that changes in backpack weight would lead to different muscular and foot reactions in flatfoot.

\section{SUBJECTS AND METHODS}

Twelve young flatfoot subjects (as determined with RS scan system as described below) and 14 normal foot subjects participated in this study. An explanation of the study was given, and all of the subjects consented to voluntary participation in the experiment. This study proceeded after review and approval by the Clinical Research and Ethics Review Committee of the National Evidence-based Health- 
care Collaborating Agency. The exclusion criteria included recent injury, postural deformities, spine surgery, history of low back pain and major surgery during the last 6 months.

In each session, the subjects were assigned to carry four different backpack loads: (1) unloaded walking (0\%), (2) $10 \%$ body weight (BW) load, (3) 15\% BW load, and (4) $20 \%$ BW load. The same backpack was used during all loaded walking modes for all subjects. Trunk and lower extremity muscle activities were recorded by surface EMG, and contact area and plantar foot pressure were determined using a RS scan system.

First, the rectus abdominis (RA), erector spinae (ES), vastus medialis (VM), biceps femoris (BF), tibialis anterior (TA), and gastrocnemius medialis (GM) muscle activities were recorded using surface EMG (Delsys Inc., Boston, MA, USA). After standard preparation, disposable silver/ silver-chloride bipolar surface electrodes were attached to the muscle bellies. Before electrode attachment, the skin surface was slightly abraded with sand paper and wiped with rubbing alcohol to facilitate better attachment with reduced skin-electrode impedance. (data gain 1,000, bandpass filter $20-450 \mathrm{~Hz}, \mathrm{CMRR}>100 \mathrm{db}$ at $60 \mathrm{~Hz}$, input impedance $>100 \mathrm{MX}$ ).

Plantar foot pressure was measured by using an RSscan system (RSscan Deutchland, Leipzig, Germany). The participants were asked to walk barefoot at a comfortable speed on a 2-m-long plate. Data regarding the pressure distribution while walking were collected at a rate of 126 frames/

Table 1. General characteristics of subjects

\begin{tabular}{lcc}
\hline & $\begin{array}{c}\text { Flatfoot group } \\
(\mathrm{n}=14)\end{array}$ & $\begin{array}{c}\text { Control group } \\
(\mathrm{n}=12)\end{array}$ \\
\hline Age $(\mathrm{yrs})$ & $22.0 \pm 0.7$ & $23.1 \pm 0.7$ \\
Height $(\mathrm{cm})$ & $163.8 \pm 1.7$ & $168.8 \pm 2.2$ \\
Weight $(\mathrm{kg})$ & $57.1 \pm 3.3$ & $64.2 \pm 2.1$ \\
Gender $(\mathrm{m} / \mathrm{f})$ & $8 / 6$ & $7 / 5$ \\
\hline
\end{tabular}

Values are mean $\pm \mathrm{SE}$ sec using the Footscan 7 gait 2nd generation software, which is a commercial program for the RSscan system. For each trial, 10 anatomical pressure subareas were automatically identified on the peak pressure footprint. The subareas were the medial heel, lateral heel, and metatarsal joints.

Two-way ANOVA was performed on the parameters of muscle activities and plantar foot pressure for walking with all backpack weights. To identify the main significant effect, the LSD test was utilized to get the specific mean differences. All statistical tests were performed with the SPSS 21.0 statistical analysis software, and results were considerd significant at $\mathrm{p}<0.05$.

\section{RESULTS}

There were 26 subjects (14 with flatfoot/12 with normal foot); and their general characteristics are shown in Table 1. There were no statistically significant differences between the two groups $(\mathrm{p}>0.05)$.

Table 2 shows the EMG activities of trunk and lower extremity muscles during the different gait conditions. In the flatfoot group, there were no significant changes during the different walking modes in the BF and RA ( $p>0.05)$. However, the ES, VM, TA, and GM muscle activities were significantly and progressively as the load increased $(\mathrm{p}<0.05)$. In the normal foot group, there were no significant changes in the BF, RA, and ES ( $p>0.05)$, but the VM, TA, and GM muscle activities were significantly increased $(p<0.05)$.

The contact area of forefoot, midfoot, and hindfoot were significantly and progressively different with load in both groups $(p<0.05)$ (Table 3$)$. Regarding the peak pressure, only the pressures of lateral and medial heel zones of flatfoot subjects were significantly and progressively increased as the load increased $(\mathrm{p}<0.05)$ (Table 4$)$.

\section{DISCUSSION}

The objective of this study was to measure the changes in muscular activity of the trunk and lower extremities and in sole pressure by applying walking loads as a proportion

Table 2. Comparison of EMG activities of trunk and lower extremity muscles during the different gait conditions in both groups

\begin{tabular}{llcccc}
\hline Muscle & Group & $0 \%$ & $10 \%$ & $15 \%$ & $20 \%$ \\
\hline \multirow{2}{*}{ VM } & Flatfoot* & $35.2 \pm 4.6$ & $44.8 \pm 5.7$ & $46.2 \pm 5.7$ & $47.1 \pm 6.7$ \\
& Normal* $^{*}$ & $33.6 \pm 3.4$ & $35.2 \pm 6.7$ & $38.7 \pm 3.9$ & $45.7 \pm 2.8$ \\
GM & Flatfoot* & $29.0 \pm 4.6$ & $33.8 \pm 5.3$ & $36.1 \pm 5.3$ & $37.8 \pm 5.9$ \\
& Normal* $^{*}$ & $27.6 \pm 2.7$ & $31.7 \pm 3.5$ & $34.5 \pm 2.6$ & $36.7 \pm 4.5$ \\
TA & Flatfoot* & $37.9 \pm 5.5$ & $44.8 \pm 6.5$ & $40.3 \pm 4.6$ & $30.3 \pm 7.1$ \\
& Normal* & $39.4 \pm 4.2$ & $37.7 \pm 2.6$ & $40.8 \pm 6.8$ & $41.0 \pm 3.6$ \\
BF & Flatfoot & $23.3 \pm 2.8$ & $24.4 \pm 3.7$ & $29.0 \pm 4.5$ & $27.2 \pm 3.4$ \\
& Normal & $25.6 \pm 3.8$ & $24.8 \pm 2.8$ & $26.7 \pm 7.2$ & $26.2 \pm 2.3$ \\
ES & Flatfoot* & $36.3 \pm 3.5$ & $41.5 \pm 4.2$ & $45.3 \pm 4.9$ & $46.3 \pm 5.6$ \\
& Normal & $38.6 \pm 6.3$ & $37.5 \pm 5.1$ & $39.6 \pm 4.0$ & $41.2 \pm 3.4$ \\
RA & Flatfoot & $18.7 \pm 1.3$ & $23.0 \pm 2.8$ & $22.2 \pm 3.2$ & $25.1 \pm 2.7$ \\
& Normal & $20.1 \pm 3.8$ & $23.1 \pm 2.7$ & $22.5 \pm 1.6$ & $22.8 \pm 2.5$ \\
\hline
\end{tabular}

Unit: \%MVIC. Values are mean \pm SE. ${ }^{*} \mathrm{p}<0.05$ 
of body weight to patients with the flatfoot condition.

Flatfoot can cause pain, muscular fatigue, sprains at the articular capsule and ligament, and foot imbalance during daily living, including sports activities ${ }^{13)}$. It can also cause changes in the overall body position and increase the risk of back pain due to straining of muscles and effects on the pelvis, lower extremities, and even the spine in closed-chain exercise $^{14-16)}$. However, there is little research focused on load-dependent muscular activity during walking with flatfoot subjects.

In a study on normal foot subjects, the muscular activity and trunk position were shown to depend on the weight of a backpack ${ }^{6}$. Investigation of the muscular activity of the rectus, erector, biceps femoris, and vastus medialis muscles showed that the muscular activity was significantly increased only in the rectus abdominis muscle when loads of $10 \%, 15 \%$, and $20 \%$ of body weight were applied; no change was observed in other muscles. This finding was attributed to the biomechanical response whereby the rectus abdomi- nis muscle activity increases to compensate for the center of gravity (COG) movement as the body's COG moves backward due to the backpack,. In contrast, others compared muscular activity and sole pressure measurements of flatfoot and normal foot subjects and reported that the muscular activities of the tibialis anterior, gastrocnemius, peroneus brevis, and peroneus longus muscles were significantly higher in the flatfoot subjects than in the normal subjects during the swing phase and stance phase ${ }^{17)}$. Similarly, Hunt et al. ${ }^{10)}$ compared flatfoot and normal foot subjects in the stance phase and reported that muscular activity was significantly higher in the tibialis anterior, gastrocnemius, and soleus musclesof the flatfoot subjects. In this present study, the activities of the muscles used for walking increased as the load, as a proportion of body weight, increased. The increased activity was particularly significant at the vastus medialis, gastrocnemius, tibialis anterior, and erector spinae muscles. However, even though the rectus abdominis muscle activity was increased in response to the weight

Table 3. Comparison of contact area during the different gait conditions in both groups

\begin{tabular}{|c|c|c|c|c|c|}
\hline Region & Group & $0 \%$ & $10 \%$ & $15 \%$ & $20 \%$ \\
\hline \multirow{2}{*}{ Forefoot } & Flatfoot* & $51.6 \pm 0.7$ & $50.6 \pm 0.8$ & $50.6 \pm 0.6$ & $49.8 \pm 0.7$ \\
\hline & Normal* & $50.7 \pm 1.8$ & $50.4 \pm 0.7$ & $49.7 \pm 1.6$ & $48.7 \pm 0.5$ \\
\hline \multirow{2}{*}{ Midfoot } & Flatfoot* & $28.2 \pm 0.7$ & $28.5 \pm 0.9$ & $29.6 \pm 1.0$ & $30.3 \pm 1.0$ \\
\hline & Normal* & $27.4 \pm 2.1$ & $26.7 \pm 1.3$ & $27.8 \pm 1.0$ & $28.4 \pm 2.1$ \\
\hline \multirow{2}{*}{ Hindfoot } & Flatfoot* & $20.7 \pm 0.5$ & $20.6 \pm 0.5$ & $19.8 \pm 0.4$ & $19.2 \pm 0.4$ \\
\hline & Normal* & $21.9 \pm 1.1$ & $24.1 \pm 3.1$ & $22.5 \pm 1.8$ & $22.9 \pm 2.1$ \\
\hline
\end{tabular}

Values are means \pm SE. ${ }^{*} \mathrm{p}<0.05$

Table 4. Comparison of peak pressure during the different gait conditions in both groups

\begin{tabular}{lccccc}
\hline Region & Group & $0 \%$ & $10 \%$ & $15 \%$ & $20 \%$ \\
\hline \multirow{2}{*}{ Toe1 } & Flatfoot & $31.5 \pm 4.2$ & $36.9 \pm 6.5$ & $43.6 \pm 4.8$ & $39.4 \pm 5.3$ \\
& Normal & $35.4 \pm 5.4$ & $34.7 \pm 6.2$ & $40.5 \pm 5.4$ & $42.7 \pm 6.0$ \\
Toe2-5 & Flatfoot & $12.4 \pm 4.6$ & $10.9 \pm 1.7$ & $10.7 \pm 1.6$ & $13.7 \pm 2.9$ \\
& Normal & $10.3 \pm 3.4$ & $13.1 \pm 3.4$ & $11.2 \pm 0.5$ & $11.8 \pm 3.6$ \\
Meta1 & Flatfoot & $26.1 \pm 4.5$ & $29.2 \pm 5.7$ & $30.1 \pm 4.2$ & $35.6 \pm 4.7$ \\
& Normal & $28.0 \pm 2.1$ & $23.2 \pm 4.8$ & $26.1 \pm 3.4$ & $21.2 \pm 4.9$ \\
Meta2 & Flatfoot* & $38.0 \pm 4.6$ & $58.2 \pm 9.0$ & $54.7 \pm 6.1$ & $54.7 \pm 5.9$ \\
& Normal & $43.1 \pm 2.8$ & $45.8 \pm 3.1$ & $46.7 \pm 4.8$ & $49.1 \pm 2.1$ \\
Meta3 & Flatfoot & $43.4 \pm 6.7$ & $61.1 \pm 10.3$ & $48.1 \pm 6.2$ & $54.2 \pm 6.4$ \\
& Normal & $45.8 \pm 6.7$ & $50.7 \pm 6.8$ & $56.0 \pm 5.1$ & $51.2 \pm 4.1$ \\
Meta4 & Flatfoot & $19.1 \pm 4.6$ & $41.0 \pm 11.1$ & $27.5 \pm 6.8$ & $32.6 \pm 6.6$ \\
& Normal & $20.1 \pm 5.1$ & $26.1 \pm 4.4$ & $31.7 \pm 9.7$ & $34.1 \pm 5.0$ \\
Meta5 & Flatfoot & $10.9 \pm 4.8$ & $20.8 \pm 5.7$ & $18.2 \pm 6.1$ & $15.4 \pm 6.3$ \\
& Normal & $13.2 \pm 5.1$ & $17.2 \pm 3.7$ & $19.2 \pm 6.7$ & $18.4 \pm 5.5$ \\
Midfoot & Flatfoot & $4.3 \pm 0.9$ & $6.0 \pm 1.4$ & $6.5 \pm 1.7$ & $8.3 \pm 2.8$ \\
Medial & Normal & $5.7 \pm 5.1$ & $5.4 \pm 6.7$ & $7.5 \pm 2.0$ & $8.6 \pm 3.1$ \\
heel & Flatfoot* & $44.2 \pm 5.1$ & $53.8 \pm 8.2$ & $55.4 \pm 6.4$ & $65.0 \pm 6.6$ \\
Lateral & Normal & $46.4 \pm 6.7$ & $49.8 \pm 4.8$ & $48.7 \pm 6.0$ & $42.5 \pm 7.1$ \\
heel & Flatfoot* & $36.6 \pm 5.9$ & $45.5 \pm 6.3$ & $49.2 \pm 5.9$ & $51.7 \pm 6.6$ \\
\hline Valns & Normal & $40.2 \pm 3.8$ & $43.4 \pm 5.8$ & $44.7 \pm 6.7$ & $47.4 \pm 4.0$ \\
\hline
\end{tabular}

Values are mean \pm SE. ${ }^{*} \mathrm{p}<0.05$ 
load in the flatfoot persons, this increase was not statistically significant when compared with the results of another study ${ }^{6}$. The reason for this difference may be because we measured muscular activity during walking, whereas the other researchers measured muscular activity in the upright position. Additional studies should be carried out in the future to resolve this discrepancy.

The contact area in flatfoot individuals during walking increased at the midfoot in response to increasing weight loads, whereas it was significantly reduced at the forefoot and hindfoot. This result was similar to the results of a study that measured plantar pressure during walking and running depending on foot types ${ }^{18)}$. That study showed that the contacting area and the maximum force were greater at the midfoot but smaller at the forefoot, in flatfeet compared with normal feet. However, the results of this study indicate a difference in loading in the forefoot, with a significant decrease in load in the lateral forefoot in individuals with flatfoot, which is in contrast to the results presented by Sneyers et al. ${ }^{19)}$ that indicated no significant medial shift in forefoot loading.

The maximum pressure at each region during walking tended to be greater as the load increased, but a significant difference was found only for the medial and lateral heel regions. This may be because the maximum pressure at the heel was increased due to the greater impact during the initial contact phase. This finding is similar to the result reported by De Cock et al. ${ }^{20)}$, who showed that the maximum pressure at the heel became at least two times higher in response to increases in walking speed.

While plantar pressure and plantar loading are useful tools to investigate biomechanical factors influencing foot and ankle pathology, it is important to consider the limitations of such data ${ }^{17,19,21)}$. In the current study, the variations within the subject sample were minimized by including only young adult subjects with no history of foot and ankle injury or pain. The changes in muscular activity in the trunk and lower extremities and in the sole pressure were investigated in flatfoot with respect to increases in weight load. Muscular activity, contact area, and plantar pressure were significantly increased as the weight load was increased as a proportion of the body weight.

Excessive weight load increased the muscular tension in the trunk and lower extremities, resulting in a concentration of pressure on the midfoot in the flatfoot condition. These biomechanical changes may lead to musculoskeletal symptoms in lower extremities and the feet. Therefore, this research data will be useful in producing overload risk preventative measures.

\section{ACKNOWLEDGEMENT}

This paper was supported by Research Fund offered from Catholic University of Pusan in 2012.

\section{REFERENCES}

1) Hessert MJ, Vyas M, Leach J, et al.: Foot pressure distribution during walking in young and old adults. BMC Geriatr, 2005, 5: 8. [Medline] [CrossRef]

2) Perry J: Gait analysis: Normal and Pathological Function. New Jersey: SLACK, 1992.

3) Kaufman KR, Brodine SK, Shaffer RA, et al.: The effect of foot structure and range of motion on musculoskeletal overuse injuries. Am J Sports Med, 1999, 27: 585-593. [Medline]

4) Williams DS, McClay IS, Hamill J: Arch structure and injury patterns in runners. Clin Biomech (Bristol, Avon), 2001, 16: 341-347. [Medline] [CrossRef]

5) Ledoux WR, Hillstrom HJ: The distributed plantar vertical force of neutrally aligned and pes planus feet. Gait Posture, 2002, 15: 1-9. [Medline] [CrossRef]

6) Al-Khabbaz YS, Shimada T, Hasegawa M: The effect of backpack heaviness on trunk-lower extremity muscle activities and trunk posture. Gait Posture, 2008, 28: 297-302. [Medline] [CrossRef]

7) Birrell SA, Haslam RA: The effect of load distribution within military load carriage systems on the kinetics of human gait. Appl Ergon, 2010, 41: 585-590. [Medline] [CrossRef]

8) Singh T, Koh M: Effects of backpack load position on spatiotemporal parameters and trunk forward lean. Gait Posture, 2009, 29: 49-53. [Medline] [CrossRef]

9) Pascoe DD, Pascoe DE, Wang YT, et al.: Influence of carrying book bags on gait cycle and posture of youths. Ergonomics, 1997, 40: 631-641. [Medline] [CrossRef]

10) Hunt AE, Smith RM: Mechanics and control of the flat versus normal foot during the stance phase of walking. Clin Biomech (Bristol, Avon), 2004, 19: 391-397. [Medline] [CrossRef]

11) Smith B, Ashton KM, Bohl D, et al.: Influence of carrying a backpack on pelvic tilt, rotation, and obliquity in female college students. Gait Posture, 2006, 23: 263-267. [Medline] [CrossRef]

12) Lindner $T$, Schulze $C$, Woitge $S$, et al.: The effect of the weight of equipment on muscle activity of the lower extremity in soldiers. ScientificWorldJournal, 2012, 2012: 976513. [Medline] [CrossRef]

13) Richie DH Jr: Biomechanics and clinical analysis of the adult acquired flatfoot. Clin Podiatr Med Surg, 2007, 24: 617-644. [Medline] [CrossRef]

14) Lee JH, Sung IY, Yoo JY: Clinical or radiologic measurements and 3-d gait analysis in children with pes planus. Pediatr Int, 2009, 51: 201-205. [Medline] [CrossRef]

15) Burns J, Crosbie J: Weight bearing ankle dorsiflexion range of motion in idiopathic pes cavus compared to normal and pes planus feet. Foot, 2005, 15: 91-94. [CrossRef]

16) Ledoux WR, Shofer JB, Ahroni JH, et al.: Biomechanical differences among pes cavus, neutrally aligned, and pes planus feet in subjects with diabetes. Foot Ankle Int, 2003, 24: 845-850. [Medline]

17) Arai K, Ringleb SI, Zhao KD, et al.: The effect of flatfoot deformity and tendon loading on the work of friction measured in the posterior tibial tendon. Clin Biomech (Bristol, Avon), 2007, 22: 592-598. [Medline] [CrossRef]

18) Chuckpaiwong B, Nunley JA, Mall NA, et al.: The effect of foot type on in-shoe plantar pressure during walking and running. Gait Posture, 2008, 28: 405-411. [Medline] [CrossRef]

19) Sneyers CJ, Lysens R, Feys H, et al.: Influence of malalignment of feet on the plantar pressure pattern in running. Foot Ankle Int, 1995, 16: 624-632. [Medline] [CrossRef]

20) De Cock A, Willems T, Witvrouw E, et al.: A functional foot type classification with cluster analysis based on plantar pressure distribution during jogging. Gait Posture, 2006, 23: 339-347. [Medline] [CrossRef]

21) Queen RM, Mall NA, Nunley JA, et al.: Differences in plantar loading between flat and normal feet during different athletic tasks. Gait Posture, 2009, 29: 582-586. [Medline] [CrossRef] 